\title{
Comparison of Ticagrelor and Clopidogrel on Platelet Function and Prognosis of Patients with Unstable Angina
}

lin ling ( $\square$ njulinglin@163.com )

First Affiliated Hospital of Soochow University

\section{LIU Ming}

First Affiliated Hospital of Soochow University

\section{Chun}

First Affiliated Hospital of Soochow University

\section{LING Zicheng}

Shanghai University of TCM: Shanghai University of Traditional Chinese Medicine

\section{Research Article}

Keywords: ticagrelor, platelet function, prognosis, unstable angina

Posted Date: May 17th, 2021

DOI: https://doi.org/10.21203/rs.3.rs-410168/v1

License: (9) This work is licensed under a Creative Commons Attribution 4.0 International License. Read Full License 


\section{Abstract}

Objective To compare the effect of ticagrelor and clopidogrel on platelet inhibition and cardiovascular prognosis and bleeding in patients with unstable angina.

Methods Patients diagnosed as unstable angina and undergoing successful PCl were selected from January 2016 to December 2018. Totally 212 patients received ticagrelor ( $90 \mathrm{mg}$ twice daily) and 210 received clopidogrel (75mg daily). Thrombo-elastography (TEG) and light transmission aggregometry (LTA) were used to measure platelet aggregation rate (PAR) induced by adenosine diphosphate (ADP) and arachidonic acid (AA). High-sensitivity troponin T (hs-TnT), pro-brain natriuretic peptide (NT-proBNP), high-sensitivity C-reactive protein (CRP) and heart-type fatty acid binding protein(H-FABP)were measured to assess myocardium injury peri-PCl. Patients were followed up in hospital and 12 months after discharge for cardiovascular prognosis and bleeding events.

Results There were no significant differences in clinical characteristics between the two groups. Compared with clopidogrel, PAR in ticagrelor group was inhibited more significantly $(P<0.001)$. Hs-TnT, NT-proBNP, CRP, and h-FABP elevated post PCl in both groups ( $P<0.05$ vs. Pre-PCl in each group), of which hs-TnT $(P<0.001)$ and h-FABP $(P<0.001)$ in clopidogrel group elevated more significantly. Both MACE in hospital and at 12-months follow up showed no significant difference between the two groups. Total bleeding events were increased in hospital in ticagrelor group $(P<0.05)$. Both minor bleeding and total bleeding were significantly elevated at 12-month follow up in ticagrelor group $(P<0.05)$.

Conclusions Ticagrelor was effective in platelet suppression than clopidogrel and reduced peri-PCI myocardial injury in patients with unstable angina. However, ticagrelor showed no advantages in reducing in hospital and 12-months MACE and increased in hospital and 12-months bleeding events.

\section{Introduction}

Acute coronary syndrome (ACS) is a leading cause of disability and death worldwide. Dual antiplatelet therapy, including aspirin and a P2Y12 inhibitor, has become the cornerstone of current standard of treatment for ACS, especially in those undergoing percutaneous coronary intervention ( $\mathrm{PCl})$. Clopidogrel is used as a classic P2Y12 receptor antagonist worldwide [1-3]. However, clopidogrel has a slow onset of action as it needs liver metabolism. Drug resistance in some patients due to CYP2C19 gene loss of function results in a significant decrease of clopidogrel blood concentration and reduced drug effects. Ticagrelor is a new oral P2Y12 inhibitor, which acts more rapidly and reversibly. Current guidelines are more inclined to recommend ticagrelor as the choice for ACS patients. However, some studies have found contradictory results in real world which suggest no superiority of ticagrelor over clopidogrel in specific population of patients [4-6]. In patients with unstable angina pectoris, the choice of ticagrelor or clopidogrel as DAPT together with aspirin in East Asian population is still controversial. This study retrospectively analyzed the anti-platelet effect and cardiovascular outcomes between ticagrelor and clopidogrel in Chinese patients with unstable angina pectoris successfully treated with $\mathrm{PCl}$. We observed 
platelet aggregation inhibition, myocardial injury peri-PCI operative period, cardiovascular prognosis and bleeding event in hospital and 12 months of follow-up.

\section{Experimental Method}

1.1 Study design and objects. Patients diagnosed as unstable angina and undergoing successful PCI were selected from January 2016 to December 2018 in the First Affiliated Hospital of Soochow University. The selection criteria for unstable angina included initial angina, worsening exertional angina, and resting angina with or without ECG ischemia. Exclusion criteria included: 1. positive high sensitive troponin $\mathrm{T}$ at admission (> 5 times the upper limit); 2 . Patients combined with thrombocytopenia (PLT < 50*109/L) or decreased hemoglobin $(\mathrm{Hb}<10 \mathrm{~g} / \mathrm{dL})$ who did not received dual antiplatelet; 3. failure of PCl; 4. life expectancy less than 1 year. We totally enrolled 445 patients, with 422 successfully included in this study and 23 lost to follow up. Among these patients, 212 received ticagrelor dose of 90 mg twice daily and 210 received clopidogrel dose of $75 \mathrm{mg}$ daily. All patients received aspirin 100mg daily. The study was approved by the Institutional Review Board of the First Affiliated Hospital of Soochow University, and all patients signed informed consent before participation.

1.2 Data collection. Recorded basic clinical data of patient, including general conditions, comorbidities, tobacco and alcohol habits, previous bleeding history, blood routine, liver and kidney function, blood lipid levels, cardiac-markers, high-sensitive Troponin T level, echocardiogram indicators and medications. Elective percutaneous coronary revascularization (PCI) was performed and coronary artery conditions were recorded, including the number of diseased vessels, TIMI blood flow, and the number of stents and balloons.

1.3 Determination of platelet function. All patient received blood test on day 0 , day 3 and day 30 after antiplatelet medication. Platelet function induced by adenosine diphosphate (ADP) and arachidonic acid (AA) was detected by thrombo-elastography (TEG) and light transmission aggregometry (LTA). The thrombo-elastography device of Haemoscope Company (United States) and platelet function analyzer (Beyotime Biotechnology Company, China) were used.

1.4 Detection of myocardial injury after PCI. Blood samples before and 24 hours after PCI were detected for high-sensitivity troponin T (hs-TnT), NT-brain natriuretic peptide (NT-proBNP), high-sensitivity Creactive protein (CRP), and myocardial fatty acid binding protein (H-FABP). Chemiluminescence and enzyme-linked immunosorbent assay were used for detection, and the detection kit was provided by Beyotime Biotechnology Company, China.

1.5 Cardiovascular prognosis and bleeding events follow up. Cardiovascular prognosis and bleeding events were follow-up in hospital and for 12 months after discharge. Cardiovascular endpoint including: all-cause death, occurrence of myocardial infarction, target vessel revascularization, stent thrombosis, stroke, TIA and overall cardiovascular and cerebral adverse events. The Bleeding Academic Research Consortium criteria was used to define the degree of bleeding. Minor bleeding was defined as skin bruising, subcutaneous ecchymosis, nose bleed, bleeding gums; major bleeding was defined as fatal 
bleeding, significant bleeding requiring blood transfusion, or gastrointestinal bleeding, intracranial hemorrhage with hemoglobin decrease of $\geq 3 \mathrm{~g} / \mathrm{dL}$.

1.6 Statistical analysis. SPSS 22.0 software was used for statistical analysis. Measurement data were expressed as mean \pm standard deviation $(x \pm s)$. Comparison of means between groups used independent $t$ test. Count data was expressed by rate, and comparison of rates was expressed by chi-square Test, with $\mathrm{P}<0.05$ as the significant statistically difference.

\section{Results}

2.1 Basic clinical characteristics of patients. Basic clinical data, history, blood test, medications, coronary artery procedures and echocardiography indexes of patients of the two groups were listed in Table 1. There were no significant differences in these clinical indexes between the two groups.

2.2 Comparison of platelet aggregation rate. Compared with clopidogrel group, platelet aggregation rate (PAR) in ticagrelor group induced by ADP and AA decreased, and the difference between the two groups was statistically significant $\left({ }^{\star} P<0.001\right.$, Ticagrelor vs. Clopidogrel, Fig. 1,2$)$. Both TEG and LTA assay showed the same trend. Ticagrelor was more effective in platelet suppression than clopidogrel. Other TEG parameters showed that $\mathrm{R}$ value and $\mathrm{K}$ value were prolonged, $\mathrm{a}$ angle and MA value were decreased in ticagrelor group. The difference was statistically significant $\left({ }^{\star} P<0.05\right)$. The detailed data were shown in Table 2. 
Table 1

Baseline characteristics of patients

\begin{tabular}{|llll|}
\hline Index & Clopidogrel $(\mathbf{n}=\mathbf{2 1 0})$ & Ticargrelor $(\mathbf{n}=\mathbf{2 1 2})$ & $\boldsymbol{P}$ Value \\
\hline Clinical data & & & \\
\hline Male(\%) & $70 \%(147)$ & $76.41 \%(162)$ & 0.137 \\
\hline Age (y) & $62.86 \pm 15.06$ & $64.76 \pm 14.53$ & 0.237 \\
\hline Body mass index(kg/m²) & $23.92 \pm 2.37$ & $24.64 \pm 4.60$ & 0.052 \\
\hline Hypertension(\%) & $61.9 \%(130)$ & $66 \%(140)$ & 0.377 \\
\hline Diabetes(\%) & $38 \%(80)$ & $41.98 \%(89)$ & 0.415 \\
\hline Smoker(\%) & $48 \%(101)$ & $52.35 \%(111)$ & 0.381 \\
\hline Drinker(\%) & $20 \%(42)$ & $25.94 \%(55)$ & 0.147 \\
\hline Previous GI bleeding(\%) & $1.42 \%(3)$ & $0.94 \%(2)$ & 0.645 \\
\hline Peptic ulcer(\%) & $9.52 \%(20)$ & $6.13 \%(13)$ & 0.194 \\
\hline Previous CVD(\%) & $9 \%(19)$ & $12.26 \%(26)$ & 0.284 \\
\hline Hemoglobin(g/L) & $130.14 \pm 21.62$ & $129.18 \pm 29.12$ & 0.759 \\
\hline Triglyceride(mmol/L) & $2.74 \pm 1.03$ & $2.58 \pm 1.04$ & 0.133 \\
\hline Cholesterol(mmol/L) & $5.32 \pm 1.57$ & $5.11 \pm 1.29$ & 0.126 \\
\hline HDLc(mmol/L) & $1.57 \pm 0.60$ & $1.45 \pm 0.58$ & 0.064 \\
\hline LDLc(mmol/L) & $3.13 \pm 1.38$ & $2.90 \pm 1.24$ & 0.074 \\
\hline HbA1c(\%) & $5.52 \pm 0.89$ & $5.41 \pm 0.88$ & 0.215 \\
\hline Creatinine(umol/L) & $89.37 \pm 35.26$ & $87.91 \pm 30.57$ & 0.642 \\
\hline BUN(umol/L) & $6.75 \pm 2.21$ & $6.56 \pm 2.13$ & 0.085 \\
\hline ALT (U/L) & $32.18 \pm 14.61$ & $30.17 \pm 12.56$ \\
\hline CK(U/L) & $279.92 \pm 267.05$ & $238.61 \pm 183.14$ & \\
\hline Hs-TnT(ug/L) & $49.19 \pm 28.27$ & $54.13 \pm 26.22$ & \\
\hline Medications & & & 0.064 \\
\hline
\end{tabular}

GI: gastrointestinal; CVD: cardiovascular disease; HDLc: High-density cholesterol; LDLC: low-density cholesterol; HbA1c: glycated hemoglobin; BUN: urea nitrogen; ALT: alanine aminotransferase; CK: Creatine Kinase; Hs-TnT : high-sensitivity troponin T; ACEI/ARB : angiotensin converting enzyme inhibitor / angiotensin receptor antagonist; PPI: proton pump inhibition; LVEF: Left ventricular ejection fraction; LEVDd : left ventricular end-diastolic diameter; LVESd :left ventricular end-systolic diameter; LAD: left atrium diameter. 


\begin{tabular}{|c|c|c|c|}
\hline Index & Clopidogrel $(n=210)$ & Ticargrelor $(n=212)$ & $P$ Value \\
\hline Aspirin & $100 \%$ & $100 \%$ & 1 \\
\hline ACEI/ARB & $74.28 \%(156)$ & $68.39 \%(145)$ & 0.181 \\
\hline Beta-blockers & $49.52 \%(105)$ & $40.09 \%(95)$ & 0.286 \\
\hline Statins & $100 \%$ & $100 \%$ & 1 \\
\hline PPI & $100 \%$ & $100 \%$ & 1 \\
\hline \multicolumn{4}{|l|}{ Coronary procedure } \\
\hline Radial & $100 \%$ & $100 \%$ & 10 \\
\hline No. of diseased artery & $1.86 \pm 0.49$ & $1.75 \pm 0.79$ & 0.060 \\
\hline No. of Stents & $1.15 \pm 0.39$ & $1.22 \pm 0.46$ & 0.128 \\
\hline No. of Balloon & $2.1 \pm 0.32$ & $2.04 \pm 0.60$ & 0.144 \\
\hline TIMI Degree & $2.88 \pm 0.38$ & $2.86 \pm 0.45$ & 0.727 \\
\hline \multicolumn{4}{|c|}{ Echocardiography indexes } \\
\hline LVEF(\%) & $51.84 \pm 8.25$ & $53.13 \pm 9.21$ & 0.099 \\
\hline LEVDd(mm) & $53.34 \pm 6.82$ & $52.18 \pm 6.92$ & 0.067 \\
\hline LVESd(mm) & $42.67 \pm 6.17$ & $41.65 \pm 6.37$ & 0.075 \\
\hline $\mathrm{LAD}(\mathrm{mm})$ & $42.15 \pm 4.93$ & $42.94 \pm 5.08$ & 0.128 \\
\hline \multicolumn{4}{|c|}{$\begin{array}{l}\text { Gl: gastrointestinal; CVD: cardiovascular disease; HDLc: High-density cholesterol; LDLC: low-density } \\
\text { cholesterol; HbA1c: glycated hemoglobin; BUN: urea nitrogen; ALT: alanine aminotransferase; CK: } \\
\text { Creatine Kinase; Hs-TnT : high-sensitivity troponin T; ACEI/ARB : angiotensin converting enzyme } \\
\text { inhibitor / angiotensin receptor antagonist; PPI: proton pump inhibition; LVEF: Left ventricular ejection } \\
\text { fraction; LEVDd : left ventricular end-diastolic diameter; LVESd :left ventricular end-systolic diameter; } \\
\text { LAD: left atrium diameter. }\end{array}$} \\
\hline
\end{tabular}

Table 2 Platelet Aggregation Rate Comparison 


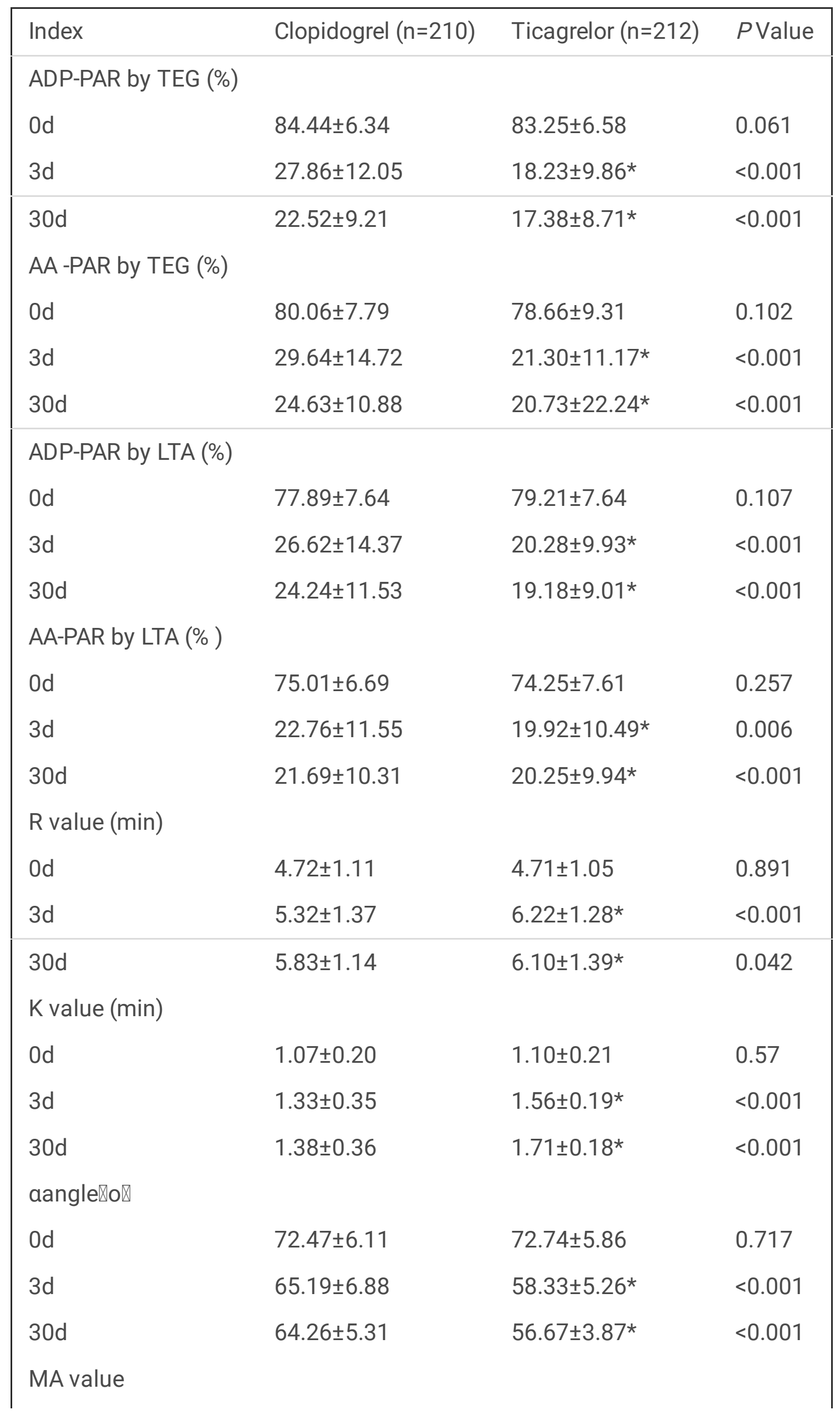




\begin{tabular}{|llll|} 
Od & $70.39 \pm 5.42$ & $71.08 \pm 3.71$ & 0.127 \\
$3 \mathrm{~d}$ & $63.06 \pm 7.64$ & $67.76 \pm 4.11 *$ & $<0.001$ \\
$30 \mathrm{~d}$ & $62.11 \pm 6.54$ & $66.56 \pm 6.67 *$ & $<0.001$ \\
\hline$* P<0.001$ Clopidogrel vs. Ticagrelor & & \\
\hline
\end{tabular}

2.3 PCl-related myocardial injury assessment

There was no significant difference between the two groups of blood hs-TnT $(49.19 \pm 28.27$ vs. $54.12 \pm$ 26.22), NT-proBNP (419.16 \pm 214.82 vs. $382.02 \pm 221.62)$, CRP ( $45.34 \pm 21.69$ vs. $43.79 \pm 18.11)$, and HFABP $(2777.01 \pm 1225.65$ vs. $2642.62 \pm 1144.05)$ levels pre-PCI $(P>0.05)$. Hs-TnT (clopidogrel : $189.08 \pm$ 101.05 vs. $49.19 \pm 28.27$, ticagrelor $122.84 \pm 67.46$ vs. $54.12 \pm 26.22$ ), NT-proBNP (clopidogrel : $1320.50 \pm$ 711.25 vs. $419.16 \pm 214.82$, ticagrelor $1265.75 \pm 863.16$ vs. $382.02 \pm 221.62$ ), CRP (clopidogrel : $161.73 \pm$ 91.46 vs. $45.34 \pm 21.69$, ticagrelor $170.97 \pm 63.26$ vs. $43.79 \pm 18.11$ ), and H-FABP (clopidogrel : $4860.63 \pm$ 1701.22 vs. $2777.01 \pm 1225.65$, ticagrelor $4465.03 \pm 1980.89$ vs. $2642.62 \pm 1144.05$ ) all elevated post PCl ( $P<0.001$ vs. pre-PCl in each group). Hs-TnT (189.08 \pm 101.05 vs. $122.84 \pm 67.46,{ }^{*} P<0.001$ vs. ticagrelor), H-FABP (4860.63 \pm 1701.22 vs. $4465.03 \pm 1980.89,{ }^{\#} P<0.05$ vs. ticagrelor) in clopidogrel group elevated significantly higher. (Fig. 3).

2.4 Cardiovascular prognosis and bleeding events follow-up. Cardiovascular prognosis of the two groups was followed up in hospital and for 12 months, including: all-cause death, occurrence of myocardial infarction, target vessel revascularization, stent thrombosis, stroke, TIA and overall MACCE. Patients in ticagrelor group had a trend of less cardiovascular event but MACE in hospital and MACE at 12-months follow up showed no significant difference between the two groups (Table 3). Total bleeding events were more in hospital in ticagrelor group ( ${ }^{*} P<0.05$ vs. clopidogrel). Both minor bleeding and total bleeding were significantly elevated at 12 -month follow up in ticagrelor group $\left({ }^{\star} P<0.05\right.$ vs. clopidogrel, Table 4$)$. 
Table 3

Cardiovascular prognosis follow-up

\begin{tabular}{|llll|}
\hline Endpoints & Clopidogrel $(\mathbf{n = 2 1 0 )}$ & Ticagrelor $(\mathbf{n = 2 1 2})$ & Pvalue \\
MACE in hospital & & & 0.995 \\
All-cause mortality (n) & 1 & 1 & 0.154 \\
MI (n) & 2 & 0 & 0.310 \\
TVR (n) & 3 & 1 & 0.314 \\
Stent thrombosis (n) & 1 & 0 & 0.158 \\
Stroke/TIA (n) & 0 & 2 & 0.351 \\
Overall MACCE (n) & 7 & 4 & \\
MACE at 12-month follow up & & & 0.557 \\
All-cause mortality (n) & 3 & 1 & 0.645 \\
MI (n) & 3 & 2 & 0.512 \\
TVR (n) & 8 & 4 & 0.314 \\
Stent thrombosis (n) & 1 & 0 & 0.992 \\
Stroke/TIA (n) & 2 & 2 & 0.100 \\
Overall MACCE (n) & 17 & 9 & \\
MACE: Major adverse cardiac events; MI: Myocardial infarction; & TVR: Target vessel revascularization; \\
MACCE: Major adverse cardiac and cerebral events. & & \\
\hline
\end{tabular}


Table 4

Bleeding events Follow-Up

\begin{tabular}{|llll|}
\hline Endpoints & Clopidogrel $(\mathrm{n}=210)$ & Ticagrelor $(\mathrm{n}=212)$ & $P$ value \\
\hline Bleedings in hospital & & & \\
Major bleeding (n) & 1 & 2 & 0.568 \\
Minor bleeding (n) & 22 & 36 & 0.052 \\
Any bleeding (n) & 23 & 38 & $0.042^{*}$ \\
Bleedings at 12-month follow up & & & \\
Major bleeding (n) & 2 & 4 & 0.418 \\
Minor bleeding (n) & 25 & 45 & $0.01^{\star}$ \\
Any bleeding (n) & 27 & 49 & $0.006^{*}$ \\
$\star *<0.05$ Ticagrelor vs. Clopidogrel & & \\
\hline
\end{tabular}

\section{Discussion}

Antiplatelet therapy has become the cornerstone of the current standardized treatment of acute coronary syndromes [7]. Clopidogrel is widely used as one of the DAPT therapy. It has certain limitations, mainly including the following aspects: 1 . As a prodrug, clopidogrel needs to be metabolized by liver enzymes after oral administration, which leads to its slow onset of action. It cannot achieve rapid inhibition of platelets in patients with acute myocardial infarction that require emergency surgery. 2 . Clopidogrel metabolism is inconsistent in different patients. Due to individual genetic differences and other reasons, some patients have clopidogrel metabolic resistance, resulting in the drug's anti-platelet effect cannot be effectively exerted, and ischemic events increase in these patients; 3 . Clopidogrel caused irreversible platelet aggregation, which leads to a longer recovery time of platelet function after clopidogrel stopped, and it cannot be used in patients who need to quickly reverse the antiplatelet effect. Ticagrelor is a reversible P2Y12 receptor antagonist. Its effect does not need to be metabolized by the liver, and acts very rapidly. Differences in individual genes do not affect the efficacy of the ticagrelor. Ticagrelor can quickly inhibit platelet aggregation [8-11].

The PLATO trial compared ticagrelor with clopidogrel in high-risk ACS patients, and the results showed that the use of ticagrelor decreased the incidence of primary composite endpoint of CV death/myocardial infarction/stroke. There was no significant difference in overall severe bleeding. Based on PLTAO trial, the current world guidelines recommend the use of ticagrelor prior to clopidogrel in ACS patients [12-14]. In recent years, the use of ticagrelor increased fast in Asian country in ACS patients, including unstable angina pectoris and myocardial infarction, however, the clinical outcomes and bleeding risk of ticagrelor 
in this population is unknown. There are few studies about the platelet aggregation function and $\mathrm{PCl}$ related myocardial injury in patients with unstable angina. Our study aims to investigate this.

The results of our study showed that compared with clopidogrel group, platelet aggregation rate induced by ADP and AA decreased significantly in ticagrelor group after medication treatment, with prolonged $\mathrm{R}$ value and $\mathrm{K}$ value, decreased $\mathrm{a}$ angle and MA value. This suggested that ticagrelor is more effective in inhibiting platelet aggregation and activation. ONSET/OFFSET studies have shown [18] that platelet aggregation rate is $60 \%$ half an hour after a loading dose of $180 \mathrm{mg}$ ticagrelor, and platelet aggregation rate is only $10 \%$ after $2-4$ hours of administration, and the corresponding platelet inhibition rate is $90 \%$. In this study, two time points, 3 day and 30 day after medication, were selected to determine platelet aggregation rate, which represented steady-state concentration of the drug. Results showed that platelet aggregation rate induced by ADP were $18.23 \pm 9.86 \%(3 \mathrm{~d})$ and $17.38 \pm 8.71 \%(30 \mathrm{~d})$ after medication in ticagrelor group assessed by TEG. Platelet aggregation rates induced by AA were $21.30 \pm 11.17 \%(3 \mathrm{~d})$ and $20.73 \pm 22.24 \%$ (30d). LTA assay showed the same trend of result. Platelet aggregation rate induced by ADP in ticagrelor group were $20.28 \pm 9.93 \%(3 d)$ and $19.18 \pm 9.01 \%(30 d)$ after medication. Platelet aggregation rates induced by AA were $19.92 \pm 10.49 \%$ (3d) and $20.25 \pm 9.94 \%$ (30d) after medication. Compared with clopidogrel group, platelet aggregation rate in ticagrelor group induced by ADP and AA decreased, and the difference between the two groups was statistically significant. This result reflects that ticagrelor can continuously and steadily inhibit platelet activation more effectively than clopidogrel, which is in consistent with the platelet aggregation rate of the drugs in the ONSET/OFFSET study [15]. Platelet aggregation induced by AA depends on the activity of the cyclooxygenase-1 (COX1) enzyme. Both ticagrelor and clopidogrel inhibit the P2Y12 receptor, which is downstream of the COX-1 pathway. Our results indicate that ticagrelor may be superior to clopidogrel not only in inhibiting ADP-induced platelet aggregation, but also in inhibiting AA-induced platelet aggregation.

PCl-related myocardial injury is very common, because the operation itself may cause further damage to the plaque or thrombus on the inner wall of the coronary artery, increasing the risk of recurrent myocardial ischemia and myocardial injury after PCl. Recent study showed that compared with clopidogrel, loading dose pretreatment of ticagrelor can significantly reduce the incidence of PCl-related periprocedural myocardial infarction (PMI) in Asian ACS patients undergoing elective PCl. Multivariate analysis found that the use of ticagrelor was negatively correlated with PCl-related PMI, indicating that ticagrelor treatment is an independent protective predictor of PMI. PCl-related PMI which was defined by an elevation of cardiac high-sensitivity troponin T values more than five times the 99th percentile upper reference limit [16]. High-sensitivity troponin $T$ is recognized as a specific indicator that reflects myocardial injury. H-FABP leaks from the cell when myocardial cells are damaged. Both are sensitive indicators of myocardial injury. Previous studies have reported that peripheral blood H-FABP level of patients with myocardial infarction is related to the severity of coronary artery disease, and can be used to assess the area of myocardial infarction and cardiovascular prognosis in patients with acute STsegment elevation myocardial infarction [17]. The results of our study suggest that the increase in hs-TnT and $\mathrm{H}-\mathrm{FABP}$ after $\mathrm{PCl}$ in the ticagrelor group was significantly lower than that in the clopidogrel group. It 
reflects the corresponding protection of myocardial damage, which has positive significance for the maintenance and protection of cardiac function.

Cardiovascular prognosis following up showed that patients in ticagrelor group had a trend of less cardiovascular event but both MACE in hospital and MACE at 12-months showed no significant difference between the two groups. Bleeding events were more common in hospital and at 12-month follow up in ticagrelor group. This correlated with several recent studies, which also conducted the same conclusions. Clopidogrel is proved noninferior to ticagrelor in cardiovascular outcomes with less bleeding in several population, including older patients $>70$ years with ACS, STEMI patients, intensive care unit patients with ACS, NSTE-ACS patients, ACS patients underwent PCI, NSTE-ACS old patients in combination use of NOAC and so on [18-23]. More and more real-world evidence showed that ticagrelor has the same clinical cardiovascular benefit with clopidogrel but a higher bleeding risk. Clopidogrel may find its role in more high-bleeding risk situation.

In conclusion, our study proved that ticagrelor was effective in platelet suppression than clopidogrel and may reduce peri-PCI myocardial injury in patients with unstable angina. However, ticagrelor showed no advantages in reducing in hospital and 12-months MACE and increased in hospital and 12-months bleeding events.

\section{Declarations}

Compliance with Ethical Standards: Research involving human participants and/or animals: All procedures performed in studies involving human participants were in accordance with the ethical standards of the institutional research committee and with the 1964 Helsinki declaration and its later amendments or comparable ethical standards. Informed consent was obtained from all individual participants included in the study.

We declared that (1) the paper is not under consideration elsewhere; (2) none of the paper's contents have been previously published; (3) all authors have read and approved the manuscript; (4) the full disclosure of any relationship with industry.

Data availability statement: The data used to support the findings of this study are available from the corresponding author upon request.

Disclosure of potential conflicts of interest: All author declare that we have no conflict of interest.

Funding: There is no funding for the article at present.

Author's Contribution: LL and LC analyzed and interpreted the patient data. LM performed patient follow up. LZ and LL were major contributors in writing the manuscript. All authors read and approved the final manuscript. 


\section{References}

1. Mohareb MW, AbdElghany M, Zaki HF, El-Abhar HS. Diabetes. and CYP2C19 Polymorphism Synergistically Impair the Antiplatelet Activity of Clopidogrel Compared With Ticagrelor in Percutaneous Coronary Intervention-treated Acute Coronary Syndrome Patients. J Cardiovasc Pharmacol. 2020 Oct;76(4):478-88. PubMed PMID: 32675750.

2. Liu Z, Tian R, Wang Y, Chen Q, Li J, Xu L, Zhang S. Platelet Inhibition with Ticagrelor versus Clopidogrel in Diabetic Patients after Percutaneous Coronary Intervention for Chronic Coronary Syndromes. Thrombosis and haemostasis. 2020 Aug;120(8):1221-9. PubMed PMID: 32668483.

3. Biswas M, Kali MSK, Biswas TK, Ibrahim B. Risk of major adverse cardiovascular events of CYP2C19 loss-of-function genotype guided prasugrel/ticagrelor vs clopidogrel therapy for acute coronary syndrome patients undergoing percutaneous coronary intervention: a meta-analysis. Platelets. 2020 Jul 14:1-10. PubMed PMID: 32664772.

4. Xu F, Feng W, Zhou Z, Zhang Y, Diao X, Hu S, Zheng Z. Antiplatelet effects of ticagrelor versus clopidogrel after coronary artery bypass graft surgery: A single-center randomized controlled trial. J Thorac Cardiovasc Surg. 2019 Aug;158(2):430-7. e4. PubMed PMID: 30501950.

5. Li J, Qiu H, Yan L, Guo T, Wang Y, Li Y, Zheng J, Tang Y, Xu B, Qiao S, Yang Y, Gao R. Efficacy and Safety of Ticagrelor and Clopidogrel in Patients with Stable Coronary Artery Disease Undergoing Percutaneous Coronary Intervention. Journal of atherosclerosis and thrombosis. 2020 Sep 8. PubMed PMID: 32908113.

6. Chang CJ, Tung YC, Liu JR, Chang SH, Kuo CT, See LC. Efficacy and Safety of Ticagrelor vs. Clopidogrel in East Asian Patients with Acute Myocardial Infarction: A Nationwide Cohort Study. Clinical pharmacology and therapeutics. 2021 Feb;109(2):443-51. PubMed PMID: 32767756.

7. Hamilos M, Kanakakis J, Anastasiou I, Karvounis C, Vasilikos V, Goudevenos J, Michalis L, Koutouzis M, Tsiafoutis I, Raisakis K, Stakos D, Hahalis G, Vardas P. Collaborators. Ticagrelor versus Clopidogrel in patients with STEMI treated with thrombolysis: the MIRTOS trial. Eurolntervention: journal of EuroPCR in collaboration with the Working Group on Interventional Cardiology of the European Society of Cardiology. 2020 Jul 21. PubMed PMID: 32715996.

8. Thor.Ueland, Axel.Åkerblom TatevikGhukasyan, et al. Osteoprotegerin is Associated With Major Bleeding but Not With Cardiovascular Outcomes in Patients With Acute Coronary Syndromes Insights From the PLATelet Inhibition and Patient Outcomes (PLATO) Trial[J]. Journal of American Heart Association. 2018;7(2):e007009.

9. Bergmark BA. Real-World Comparison of Ticagrelor and Clopidogrel: Rosetta Stone or Lost in Translation? Journal of the American Heart Association. 2020 Jul 21;9(14):e017888. PubMed PMID: 32662331. Pubmed Central PMCID: 7660703.

10. Xue Y, Hu Z, Jing Y, Wu H, Li X, Wang J, Seybert A, Xie X, Lv Q. Efficacy assessment of ticagrelor versus clopidogrel in Chinese patients with acute coronary syndrome undergoing percutaneous coronary intervention by data mining and machine-learning decision tree approaches. J Clin Pharm Ther. 2020 Oct;45(5):1076-86. PubMed PMID: 32627223. 
11. Sun Y, Li C, Zhang L, Yu T, Ye H, Yu B, Tao M, Jiang J, Yan J, Wang Y, Zeng H, Shen X, Wang DW. Clinical outcomes after ticagrelor and clopidogrel in Chinese post-stented patients. Atherosclerosis. 2019 Nov;290:52 - 8. PubMed PMID: 31568962.

12. Russo JJ, James TE, Ruel M, Dupuis JY, Singh K, Goubran D, Malhotra N, Rubens F, Chong AY, Hibbert B, Boland P, Tran DT, Tanguay JF, Lordkipanidze M, Perrault L, Wells GA, Bourke M, Chan V, So DY. Ischemic and bleeding outcomes after coronary artery bypass grafting among patients initially treated with a P2Y12 receptor antagonist for acute coronary syndromes: Insights on timing of discontinuation of ticagrelor and clopidogrel prior to surgery. European heart journal Acute cardiovascular care. 2019 Sep;8(6):543-53. PubMed PMID: 29313713.

13. Soize S, Foussier C, Manceau PF, Litre CF, Backchine S, Gawlitza M, Pierot L. Comparison of two preventive dual antiplatelet regimens for unruptured intracranial aneurysm embolization with flow diverter/disrupter: A matched-cohort study comparing clopidogrel with ticagrelor. Journal of neuroradiology = Journal de neuroradiologie. 2019 Nov;46(6):378-83. PubMed PMID: 30731144.

14. Hagstrom E, James SK, Bertilsson M, et al. Growth differentiation factor-15 level predicts major bleeding and cardiovascular events in patients with acute coronary syndromes: results from the PLATO study[J]. Eur Heart J. 2016;37(16):1325-33.

15. NORA TOMA. Randomized double-blind assessment of the ONSET and OFFSET of the antiplatelet effects of Ticagrelor versus Clopidogrel in patients with stable coronary artery disease. The ONSET/OFFSET study [J]. Maedica, 2010,5(1):75-76.

16. Shimada YJ, Bansilal S, Wiviott SD, et al. Impact of glycoprotein Ilb/Illa inhibitors on the efficacy and safety of ticagrelor compared with clopidogrel in patients with acute coronary syndromes: Analysis from the Platelet Inhibition and Patient Outcomes (PLATO) Trial[J]. Am Heart J. 2016;177(2):1-8.

17. Zhang YR, Xue ZK, Chen KY, Xu LX, Wang WD, Tao HY, Liu T, Che JJ, Wang XW, Rha SW, Wang JR, Wang P. Loading doses of ticagrelor versus clopidogrel in preventing periprocedural myocardial infarction in Asian patients with acute coronary syndrome. Perfusion. 2020 Jun 10:267659120927857. PubMed PMID: 32522095.

18. Shabaiek A, Ismael Nel H, Elsheikh S, Amin HA. Role of Cardiac Myocytes Heart Fatty Acid Binding Protein Depletion (H-FABP) in Early Myocardial Infarction in Human Heart (Autopsy Study). Open access Macedonian journal of medical sciences. 2016 Mar 15;4(1):17-21. PubMed PMID: 27275322. Pubmed Central PMCID: 4884241.

19. Li J, Qiu H, Yan L, Guo T, Wang Y, Li Y, Zheng J, Tang Y, Xu B, Qiao S, Yang Y, Gao R. Efficacy and safety of ticagrelor and clopidogrel in East Asian patients with coronary artery disease undergoing percutaneous coronary intervention. Curr Med Res Opin. 2020 Nov;36(11):1739-45. PubMed PMID: 32945695.

20. Volz S, Petursson P, Odenstedt J, loanes D, Haraldsson I, Angeras O, Dworeck C, Hirlekar G, Myredal A, Albertsson P, Ramunddal T, Redfors B, Omerovic E. Ticagrelor is Not Superior to Clopidogrel in Patients With Acute Coronary Syndromes Undergoing PCl: A Report from Swedish Coronary 
Angiography and Angioplasty Registry. Journal of the American Heart Association. $2020 \mathrm{Jul}$ 21;9(14):e015990. PubMed PMID: 32662350. Pubmed Central PMCID: 7660716.

21. Alfredsson J, Omar K, Csog J, Venetsanos D, Janzon M, Ekstedt M. Bleeding complications with clopidogrel or ticagrelor in ST-elevation myocardial infarction patients - A real life cohort study of two treatment strategies. International journal of cardiology Heart vasculature. 2020 Apr;27:100495. PubMed PMID: 32309533. Pubmed Central PMCID: 7154313.

22. Charpentier T, Ferdynus C, Lair T, Cordier C, Brulliard C, Valance D, Emery M, Caron M, Allou N, Allyn J. Bleeding risk of ticagrelor compared to clopidogrel in intensive care unit patients with acute coronary syndrome: A propensity-score matching analysis. PloS one. 2020;15(5):e0232768. PubMed PMID: 32365100. Pubmed Central PMCID: 7197796.

23. Huynh K. Clopidogrel is a favourable alternative to ticagrelor in older patients with NSTE-ACS. Nature reviews Cardiology. 2020 Jul;17(7):384. PubMed PMID: 32404962.

24. Gimbel ME, Tavenier AH, Bor W, Hermanides RS, de Vrey E, Heestermans T, Gin MTJ, Waalewijn R, Hofma S, den Hartog F, Jukema W, von Birgelen C, Voskuil M, Kelder J, Deneer V, Ten Berg JM. Ticagrelor Versus Clopidogrel in Older Patients with NSTE-ACS Using Oral Anticoagulation: A SubAnalysis of the POPular Age Trial. Journal of clinical medicine. 2020 Oct 12;9(10). PubMed PMID: 33053622. Pubmed Central PMCID: 7601891.

\section{Figures}

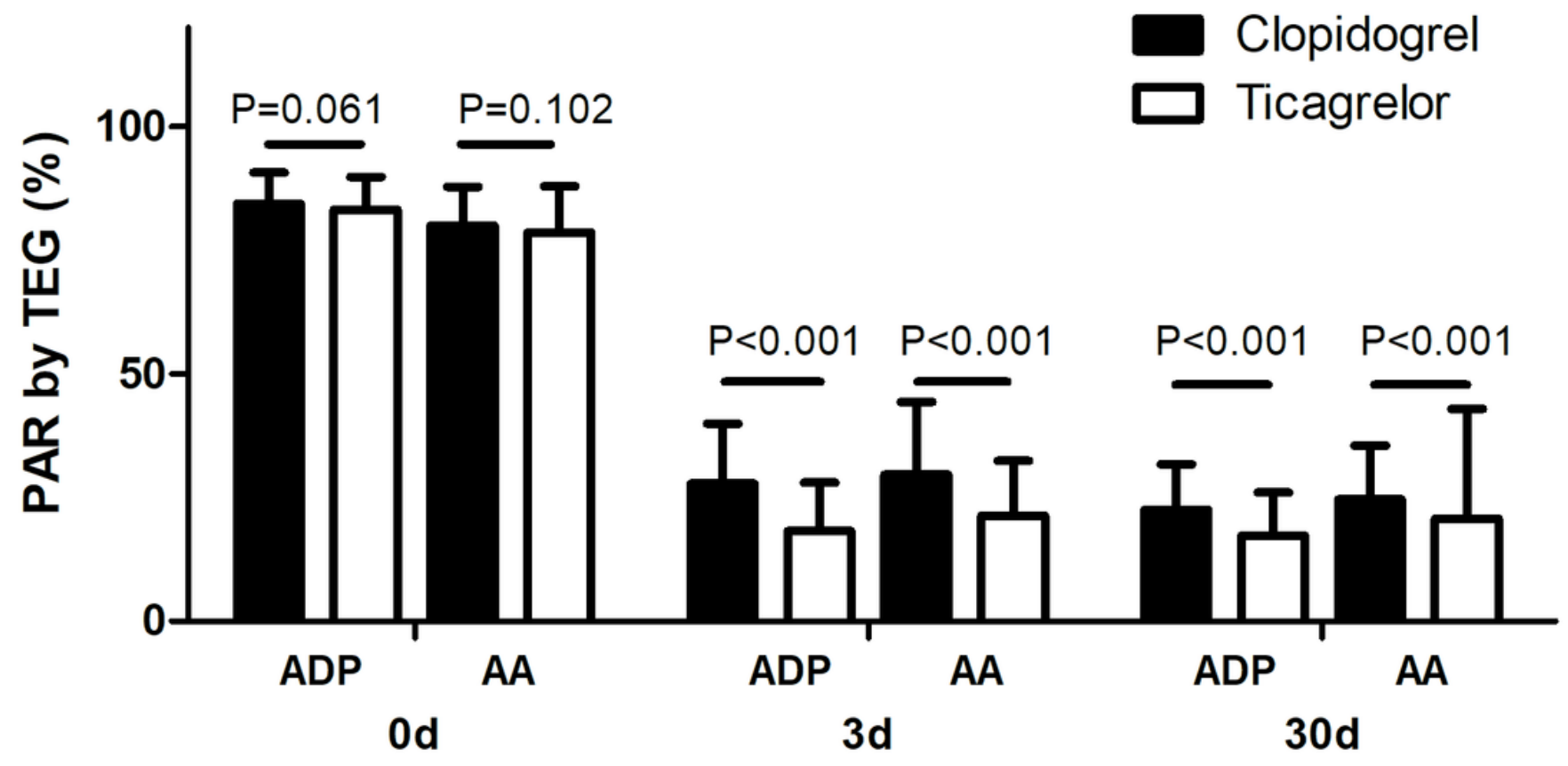

Figure 1 
Platelet aggregation rate (PAR) assessed by TEG at different time points. On $3 \mathrm{~d}$ and $30 \mathrm{~d}$, platelet aggregation rate in ticagrelor group decreased significantly $\left({ }^{*} P<0.001\right)$.
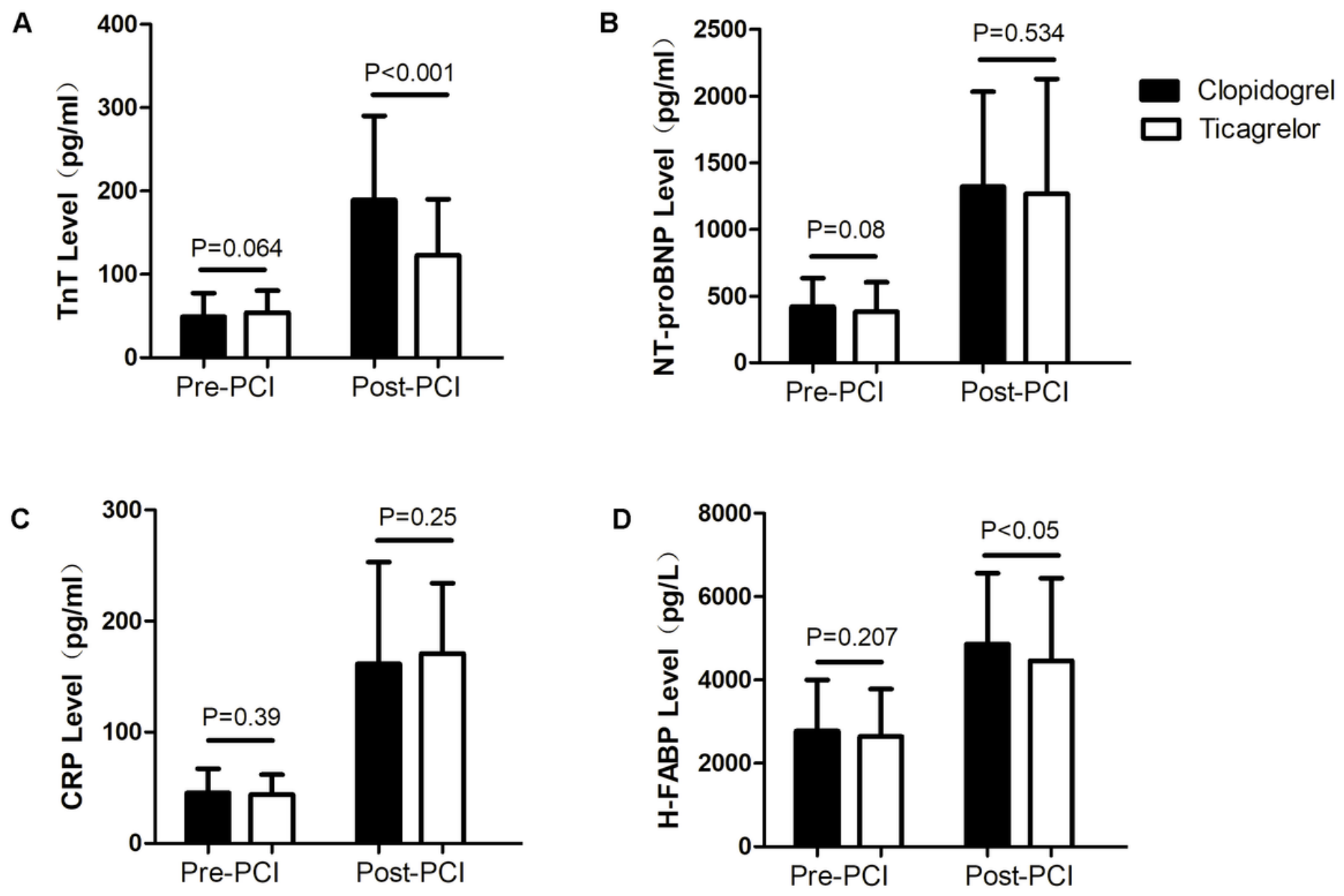

Figure 2

Platelet aggregation rate (PAR) assessed by LTA at different time points. On $3 \mathrm{~d}$ and $30 \mathrm{~d}$, platelet aggregation rate in ticagrelor group decreased significantly $\left({ }^{*} \mathrm{P}<0.001\right)$. 


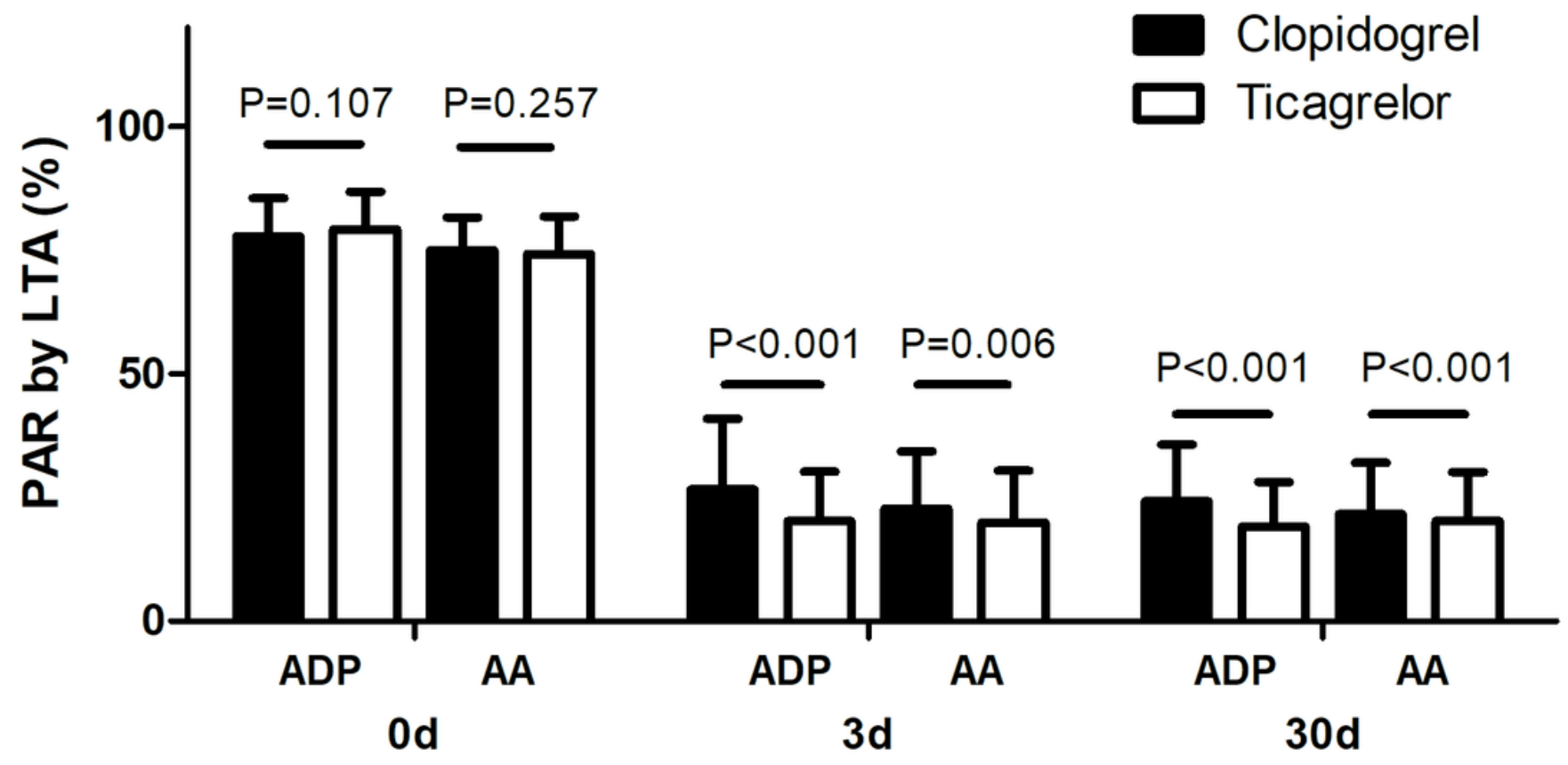

Figure 3

Blood hs-TnT, NT-proBNP, CRP, and H-FABP levels pre- and post-PCl. hs-TnT, NT-proBNP, CRP, and H-FABP all elevated post $\mathrm{PCl}(\mathrm{P}<0.05$ vs. Pre-PCl in each group). Hs-TnT $(P<0.001)$, and H-FABP $(P<0.001)$ in clopidogrel group elevated more significantly than that in ticagrelor group. 